\title{
Efficacy of Cervical Spine Muscle Strength Training in the Prevention of Cervical Spine Injuries in Hockey Players: A Critically Appraised Topic
}

\author{
Christopher Costa ${ }^{1}$
}

${ }^{1}$ Concordia University, Chicago.

\section{ABSTRACT}

From 1948 through 2011, 355 documented cases of spinal cord injuries to were reported in ice hockey players, of which $78.9 \%$ were indicative of damage to the cervical spine. ${ }^{1}$ Tyrakowski and colleagues report a high incidence of cervical spine injuries occur during contact sports, such as football and hockey. ${ }^{6}$ In contrast, additional evidence purports that contact sports injuries only represent $8.9 \%$ of total spinal cord injuries reported annually. ${ }^{5}$ Hockey presented a particularly high incidence of spinal cord and cervical spine injuries. ${ }^{2}$ Therefore, the goal of this brief review is to examine how muscle strength of the neck, cervical stabilization and range of motion (ROM) impacts cervical spine injuries. Additionally, acquiring a baseline strength analysis may elucidate the propensity towards neck related injuries in hockey players. A collection of baseline ROM should be collected at the beginning of each season and used to measure percent baseline scale. The percent baseline scale could be used to delineate the percentage of return to baseline for the purpose of understanding an appropriate timeline.

\section{INTRODUCTION}

Injury data collected from collegiate ice hockey teams throughout the period of 2009 to 2015 revealed the prevalence of 323 back, neck, and spinal injuries. ${ }^{3}$ Of these injuries, many were localized to the lumbar spine occurring during competition, indicating that cervical spine injuries were not common. Findings revealed mixed evidence supporting the occurrence of cervical spine injuries within ice hockey. ${ }^{1,2,3,5,6}$ Individuals competing in contact sports are susceptible to exhibiting a distortion of the cervical spinal column, which may result in damage to the spinal cord. ${ }^{4}$ Further difficulty in assessing individuals immediately following a perceived spinal cord injury is exacerbated due to excessive equipment (e.g., helmet, shoulder pads). Upon diagnosis and treatment, athletes generally returned to play once they have retained full ROM. ${ }^{5}$ However, it's possible that some athletes may exhibit higher susceptibility spinal stenosis. ${ }^{6}$ Those athletes should be wary of the increased risk of cervical spine injury associated with relative spinal stenosis. ${ }^{6}$

Whether caused by blunt force trauma, either with an opponent or physical barriers or spinal stenosis, athletes must be cognizant of the potential risks associated with competing in ice hockey. Examining acceleration of head isometric strength during assessment of cervical spine musculature indicated that cervical injuries are not reduced by increasing strength of the tissues. ${ }^{7}$ In contrast, increased neck strength and neuromuscular efficiency of the cervical muscles reduced the accelerative forces of the head caused by decelerative actions, such blunt force trauma with an opponent. ${ }^{8}$ However, this improvement did not reduce the prevalence of concussion. Further, a study by Kelshaw et al. in lacrosse players examined a similar strengthening approach to the cervical muscles to prevent head impact kinematics (HIK). ${ }^{9}$ These findings did not support a reduced HIK from the cervical strength improvements. It is equally important to note, that these findings did not examine spinal cord injuries associated with HIK. ${ }^{8,9}$ Therefore, it appears that future research should focus on associated injuries to the spinal cord and brain, combined. 
Collectively, these studies reflect uncertainty as to the cause and prevalence of cervical spine injuries within ice hockey. The variance of evidence is a clear indicator that greater attention needs to be dedicated to the study and intervention methods of cervical spine injuries in ice hockey players. This Critically Appraised Topic (CAT) serves to review the most current evidence regarding effective analysis and prevention of cervical spine injuries in contact sports. Findings indicate similar head kinematics at the moment of blunt force trauma The correlation to that of hockey demonstrating similar impact velocities that exhibit change in cervical biomechanics. Ice hockey was selected due to the frequency and velocity of collision impacts that occur during competition. Such information will assist strength and conditioning practitioners by providing greater understanding of current evidence related to cervical spine injury prevalence. Unfortunately, no reliable strengthening protocol exists. Therefore, S\&C professionals will need to create independent assessments until further evidence is revealed.

\section{FOCUSED CLINICAL QUESTIONS}

Is it beneficial to improve cervical spine musculature strength to reduce the risk of cervical spines injuries, not specific to concussions?

\section{SEARCH STRATEGIES}

A database search was performance in July of 2019 With the following search terms:

- Cervical spine injuries in hockey

- Strengthening of cervical spine muscular

- Prevention of cervical spine injuries in contact sports

- Patient/client group: cervical spine injuries in hockey

- Intervention: cervical musculature strengthening

- Outcome: prevention of cervical spine injuries in contact sports

The following sources were included:

- Research in Sports Medicine

- Sports Medicine and Arthroscopy Review

- Current Sports Medicine Reports

- Operative Techniques in Sports Medicine

- Clinics in Sports Medicine

- Journal of Athletic Training

- Clinical Journal of Sports Medicine
- American Journal of Sports Medicine

- International Journal of Athletic Therapy and Training

Inclusive criterion:

- Studies that included cervical injuries in hockey

- Studies that included cervical injuries in contact sports

- Studies that described cervical injuries in athletes

- Studies that presented treatment options for cervical injuries

- Studies that included strengthening of cervical spine musculature

- Exclusionary criteria were:

- Studies that did not involve contact sports

- Studies that observed concussive analysis only

- Studies that included sports that do not require protective equipment

- Studies older than 2010

\section{EVIDENCE QUALITY ASSESSMENT}

Studies were ranked and utilized based upon their impact factor ranking via the Scientific Journal Rankings to determine the quality of the journal in question. Ten studiesutilized symptomatic volunteer subject, therefore no Physiotherapy Evidence Database (PEDro) assessment was completed. STROBE (Strengthening the reporting of observational studies in Epidemiology) was used to analyze the studies. All assessment was completed by one author.

\section{SUMMARY OF SEARCH, EVIDENCE APPRAISED, AND KEY FINDINGS}

The evidence was discovered via a purposeful investigation regarding the efficacy of cervical spine injuries in the sport of ice hockey. The conduction of this search was based upon revealing literature that proposed clinical evaluation of spinal cord injury at the cervical spine and potential methods for the prevention of these injuries. Research was excluded if it referenced the study of concussion alone related to impact and biomechanical aspects of the kinetics and kinematics. The initial search resulted in two viable studies. Expansion to cervical spine strengthening and cervical spine injuries in contact sports was necessary to acquire reliable evidence that met the inclusion criteria mentioned previously, resulting in a total of ten relevant studies. 
Three of the ten studies examined long term data of at least 5 years implicating injuries associated with the cervical spine. One study ${ }^{1}$ observed 63 years of data to compile 355 cases of cervical spine injuries. A second study ${ }^{3}$ recorded 323 spinal cord injuries in less than 6 years. All studies 1-9 reviewed only cervical spine injuries, excluding all other spinal cord injuries. Findings represent a significance of cervical spine injuries, but not specifically stating the exact type of injury sustained. Spinal cord injuries at the cervical spine are common amongst all levels of contact sports, but specifically high in hockey players. This prevalence could be a result of the direct velocity created at impact. Preventative strengthening of cervical spine musculature has not provided any promising evidence towards the reduction of spinal cord injuries at impact.

\section{RESULTS OF EVIDENCE QUALITY ASSESSMENT}

None of the studies examined utilized a randomized control group. Each study 1-9 included symptomatic or asymptomatic subjects for assessment of particular variable, e. g. cervical spine injury or cervical spine muscle strength. STROBE scores ranged from 11/20 to 15/20 for all studies.

\section{CLINICAL BOTTOM LINE}

Sufficient evidence supported the prevalence of cervical spine injuries in the sport of hockey. muscle strength and rigidity had little to no effect on the resistance of head impact acceleration. ${ }^{4}$ Regardless of linear velocity and peak angular velocity changes amongst individuals with varying isometric muscle strength of the cervical muscle, cervical spine injuries appear to be unrelated. ${ }^{8}$ Only concussion mitigation appears to be a factor when examining the resistance to impacts acting upon head movement. Three studies $^{7,8,9}$ scored $\leq 13 / 20$ indicating a risk of bias. The remaining articles, $1,2,3,4,5,6$ scored above 14/20, resulting in a rating of high quality. These studies suggest that the strengthening of neck musculature may reduce the velocity and acceleration of the head during body impact. However, strength may not have any correlation to damage caused to the cervical spinal column or cervical vertebrae. Individuals with predisposed conditions of spinal stenosis should proceed with caution when engaging in contact sports.

\section{IMPLICATIONS FOR PRACTICE, EDUCATION, AND FUTURE RESEARCH}

Contact sports, namely hockey, present a unique challenge when analyzing the mitigation and prevention of cervical spine injuries. Vertebral column injuries can be devastating and present with long term neurological issues. ${ }^{10}$ Injuries such as sprains, strains, fractures, and isthmic spondylolysis are common within the cervical, thoracic and lumbar vertebrae. Many of these injuries occur between the cervical 4 and 7 vertebrae, as a direct result of compression created during violent impacts associated with changes to head acceleration. ${ }^{10}$ A root problem within the sport of ice hockey is ineffective documentation of cervical spine injuries. ${ }^{1}$ Notably, 188 cervical spine injuries have been recorded since 1948. ${ }^{1}$ Subsequently, a formal prevention protocol has not been implemented. One significant means to prevent these injuries is through formal education of the players, coaches, and staff.

An increase of body checking from behind, direct head targeting, tripping, sliding on the ice are all factors that have been recorded as causes of cervical spine injuries. ${ }^{1}$ Interestingly, contact with the boards is the most common cause of cervical spine injuries, as opposed to direct body-to-body contact. Stricter punishment for body checking from behind has led to a reduction in the frequency of cervical spine injuries. The highest incidence of cervical spine injuries in hockey appear to be during adolescent competition, roughly 16 to 20 years of age. ${ }^{1}$ While hormones may play a role in the predominance during this chronological period, it appears that anthropometric variance may have a stronger positive correlation. As to be expected, children of this age period vastly differ in height and body composition, presenting a unique challenge. The rate of growth can lead to an increase in skating velocity, therefore increasing the potential for greater impact forces. ${ }^{1}$ Improving physiological performance appears to have little to no effect on cervical spine injuries. ${ }^{7,8,9}$ Unfortunately, little to no evidence currently exists, regarding the optimization of kinetic and kinematic actions within the cervical spine structure by way of improving muscle function, hypertrophy, or neuromuscular efficiency.

The continued documentation of cervical spine injuries in hockey is necessary to gain a clearer understanding of the current prevalence of this specific injury. It appears that cervical spine injuries are less prevalent at the professional and international levels. This could potentially be attributed to a 
greater respect for athletic competition, as well as significant improvements of motor function and control exhibited by professional hockey players. Regardless, all cases should be documented, if the intended purpose is to create a standardized protocol of prevention. Future studies should analyze biomechanical and kinetic sequencing of neck musculature and bone structure. The utilization of sEMG may present viable data to facilitate a better practical understanding of muscle firing sequence and contribution during head acceleration. The creation of reliable evidence can be applied to the scope of practice when attempting to improve physiological function. Future research may consider the cumulative effect of resistance training upper and lower extremities to improve overall coordination and muscle recruitment patterns.

Many of the studies presented documentation of cervical spine injuries, but neglected to disclose treatment protocols, as well as the return to play (RTP) program. As previously stated, players are generally allowed to return once full ROM has been regained.5 However, is this effective? Should ROM be the primary determinant factor when considering the severity of injury, loss of muscular strength, muscle size, and potential inhibition of neurological function. Determining what degree of neuromuscular function in conjunction with muscle cross-sectional size, golgi-tendon apparatus, motor unit efficiency and frequency, as well as contralateral contribution should all be factors that are considered prior to allowing a player to return to contact. Continuous education of athletes is equally necessary to create an environment conducive to the preservation and prevention of these injuries. Additionally, the analysis of equipment, both helmet shape, size, and protective construction should be considered when examining direct impacts with the boards. 


\section{REFERENCES}

1. Tator, C. H., Provvidenza, C., \& Cassidy, J. D. (2016). Update and overview of spinal injuries in canadian ice hockey, 1943 to 2011: the continuing need for injury prevention and education. Clinical Journal of Sport Medicine, 26(3), 232-238. Retrieved from http://search. ebscohost.com.cucproxy.cuchicago.edu/login.aspx?direc $\mathrm{t}=$ true\&AuthType $=$ cookie, ip,, cpid\&custid $=s 8419239 \& \mathrm{db}=\mathrm{s}$ 3h\&AN $=115186478 \&$ site $=$ ehost-live

2. Kepler, C. K., \& Vaccaro, A. R. (2012). Injuries and abnormalities of the cervical spine and return to play criteria. Clinics in Sports Medicine, 31(3), 499-508. Retrieved from http://search.ebscohost.com.cucproxy. cuchicago.edu/login .aspx?direct=true\&AuthType=cookie, ip, cpid\&custid $=$ s8419239\&db=s3h\&AN=77510401\& site= ehost-live

3. Zupon, A. B., Kerr, Z. Y., Dalton, S. L., Dompier, T. P., \& Gardner, E. C. (2018). The epidemiology of back/neck/ spine injuries in National Collegiate Athletic Association men's and women's ice hockey, 2009/2010 to 2014/2015. Research in Sports Medicine, 26(1), 13-26. https://doi.org/ 10.1080/15438627.2017.1365295

4. Langer, P. R., Fadale, P. D., \& Palumbo, M. A. (2008). Catastrophic neck injuries in the collision sport athlete. Sports Medicine \& Arthroscopy Review, 16(1), 7-15. https://doi.org/10.1097/JSA.0b013e318163be37

5. Cantu, R. C., Li, Y. M., Abdulhamid, M., \& Chin, L. S. (2013). Return to play after cervical spine injury in sports. Current Sports Medicine Reports, 12(1), 14-17. Retrieved from http://search.ebscohost.com.cucproxy.cuchicago. edu/login .aspx?direct=true\&AuthType=cookie, ip,cpid\&cus $\mathrm{tid}=\mathrm{s} 8419239 \& \mathrm{db}=\mathrm{s} 3 \mathrm{~h} \& A \mathrm{~N}=84975876 \&$ site=ehost-live

6. Tyrakowski, M., Nandyala, S. V., Marquez-Lara, A., \& Siemionow, K. (2013). Congenital and developmental anomalies of the cervical spine in athletes-current concepts. Operative Techniques in Sports Medicine, 21(3), 159-163. Retrieved from http://search.ebscohost. com.cucproxy.cuchicago.edu/login.aspx?direct=true\&Aut hType $=$ cookie, ip, cpid\&custid $=s 8419239 \& d b=s 3 h \& A N=92$ 877246\&site $=$ ehost-live

7. Mihalik, J. P., Guskiewicz, K. M., Marshall, S. W., Greenwald, R. M., Blackburn, J. T., \& Cantu, R. C. (2011). Does cervical muscle strength in youth ice hockey players affect head impact biomechanics? Clinical Journal of Sport Medicine, 21(5), 416-421. Retrieved from http:// search.ebscohost.com.cucproxy.cuchicago.edu/login.asp $x$ ?direct=true \&AuthType $=$ cookie,, p , cpid\&custid $=$ s841923 $9 \& \mathrm{db}=s 3 \mathrm{~h} \& A N=65453476 \&$ site $=$ ehost-live

8. Eckner, J. T., Oh, Y. K., Joshi, M. S., Richardson, J. K., \& Ashton-Miller, J. A. (2014). Effect of neck muscle strength and anticipatory cervical muscle activation on the kinematic response of the head to impulsive loads. American Journal of Sports Medicine, 42(3), 566-576. Retrieved from http://search.ebscohost.com.cucproxy. cuchicago.edu/login.aspx?direct=true\&AuthType=cookie, ip, , pid\&custid $=s 8419239 \& \mathrm{db}=\mathrm{s} 3 \mathrm{~h} \& A \mathrm{~N}=94744147 \&$ site $=$ ehost-live

9. Kelshaw, P., Cortes, N., Caswell, A., \& Caswell, S. V. (2018). Isometric cervical muscle strength does not affect head impact kinematics in high school boys' lacrosse. International Journal of Athletic Therapy \& Training, 23(6), 234-238. Retrieved from http://search.ebscohost.com. cucproxy.cuchicago.edu/login.aspx?direct=true\&AuthTyp $\mathrm{e}=$ cookie, ip, cpid\&custid $=$ s8419239\&db=s3h\&AN=132808 $183 \&$ site $=$ ehost-live
10. Patel, S., Vaccaro, A. R., \& Rihn, J. A. (2013). Epidemiology of spinal injuries in sports. operative techniques in sports medicine, 21(3), 146-151. Retrieved from http://search.ebscohost.com.cucproxy.cuchicago. edu/login.aspx?direct=true\&AuthType=cookie,ip,cpid\&cus tid $=s 8419239 \& d b=s 3 h \& A N=92877243 \&$ site $=$ ehost-live 